\title{
(RE)SIGNIFICAÇÃO DA IMUNIDADE TRIBUTÁRIA RECÍPROCA: A COBRANÇA DE IPTU SOBRE BENS PÚBLICOS E SEUS EFEITOS SOBRE A ARRECADAÇÃO FISCAL NA CIDADE DE IMPERATRIZ-MA
}

\author{
(RE) SIGNIFICANCE OF RECIPROCAL TAX IMMUNITY: \\ THE COLLECTION OF IPTU ON PUBLIC GOODS AND THEIR EFFECTS \\ ON TAX COLLECTION IN THE CITY OF IMPERATRIZ-MA
}

\author{
DENISSON GONÇALVES CHAVES ${ }^{1}$
}

GISELLE PACHECO LIMA ${ }^{2}$

\section{RESUMO}

As constantes decisões do Supremo Tribunal Federal são de grande importância para a aplicação e interpretação dos textos legislativos. A finalidade desse trabalho é identificar os impactos causados ao fisco municipal de Imperatriz-MA, frente a mudança de entendimento do STF no RE 601.720/ RJ, sobre a inaplicabilidade da imunidade recíproca à propriedade imóvel publica quando cedida a particulares. Trata-se de uma pesquisa empírica, com levantamento de dados e análises preliminares, sobre o sistema de arrecadação da SEFAZGO de Imperatriz-MA. A pesquisa foi realizada com levantamento bibliográfico, documental e de campo, com entrevistas preordenadas e tendo por abordagem o método qualitativo e quantitativo. 0 estudo sobre a imunidade recíproca aplicável ao IPTU permitiu a correta delimitação do campo de incidência do tributo, de igual modo, o levantamento dos conceitos e modalidades das formas de concessão dos bens públicos, permitiu a percepção da evolução da suprema corte, quanto a preservação do sistema federativo. Por mais que, a busca dos impactos do RE 601.720/RJ, na arrecadação fiscal de Imperatriz-MA não tenha alcançado os resultados pretendidos, foi possível analisar o sistema de arrecadação municipal, identificando suas falhas, e problemas e a exposição de possíveis soluções para os problemas.

PALAVRAS-CHAVE: Imunidade recíproca. IPTU. Bens Públicos. Sistema Federativo. 


\section{ABSTRACT}

The constant decisions of the Federal Supreme Court are of great importance for the application and interpretation of legislative texts. The purpose of this work is to identify the impacts caused to the municipal treasury of Imperatriz-MA in the face of the change of understanding of the STF in RE 601.720 / RJ, on the inapplicability of reciprocal immunity to public property when ceded to individuals. It is an empirical research, with data collection and preliminary analyzes on the system of collection of the Imperatriz-MA SEFAZGO. The research was carried out with a bibliographical, documentary and field survey, with preordered interviews and having as approach the qualitative and quantitative method. The study on the reciprocal immunity applicable to the IPTU allowed the correct delimitation of the tax incidence field. Likewise, the survey of the concepts and modalities of the transfer of the public goods allowed the perception of the evolution of the supreme court regarding the preservation of the system federative. Although the search for the impacts of RE 601.720 / RJ, in the tax collection of Imperatriz-MA did not achieve the desired results, it was possible to analyze the municipal collection system, identifying its failures, problems and exposure of possible solutions for they.

KEY-WORDS: Mutual immunity. IPTU. Public Goods. Federative System.

\section{INTRODUÇÃO}

Este trabalho tem como campo temático a imunidade tributária recíproca: a cobrança de IPTU sobre bens públicos e seus efeitos sobre a arrecadação fiscal em Imperatriz-MA. A justificativa acadêmica pelo presente estudo surgiu mediante o julgamento do RE 601.720/ RJ pelo Supremo Tribunal Federal (STF) onde decidiu-se pela aplicação do Imposto Predial e Territorial Urbano (IPTU) sobre um bem público que se encontrava cedido à empresa privada, entendendo que a imunidade recíproca não alcançava o imóvel, haja vista a empresa exercer uma atividade com fins lucrativos e, por conseguinte, obter uma vantagem concorrencial frente as demais empresas.

Essa pesquisa se justifica pela necessidade de se compreender o conceito de "justiça fiscal" tão veemente defendida pelos ministros da Suprema Corte no julgamento do recurso, a consequente reestruturação do sistema de arrecadação fiscal, bem como a possibilidade de aumento da arrecadação dos municípios e a probabilidade de extensão do custeio de suas despesas.

Destarte, segundo dados da Organização para Cooperação e Desenvolvimento Econômico (OCDE), em 2012 a tributação sobre a propriedade correspondia a 6\% da arrecadação no Brasil, enquanto que a do consumo chegava a $44 \%$ do total, realidade que afeta ainda diretamente a classe mais pobre do país, pois quem "ganha menos paga mais, em contraste com aquele que ganha mais e paga menos" (CURI, 2007).

Tendo em vista a relevância da mudança jurisprudencial do STF para a arrecadação fiscal do IPTU pelos Municípios, o presente estudo estabelece como problema de pesquisa: Quais os efeitos produzidos ao fisco municipal pela recente mudança jurisprudencial do STF, quanto a inaplicabilidade da imunidade recíproca à propriedade imóvel pública cedida a particulares? Assim, o objetivo geral é identificar os principais desafios que se apresentaram ao governo municipal quanto à cobrança do IPTU e a aplicabilidade da nova interpretação dada pelo STF e, para tanto, se buscará compreender o instituto da imunidade tributária recíproca 
aplicável ao IPTU, levantar as formas de cessão de bem públicos atinentes ao IPTU sobre a ótica da RE 601,720 RJ e, analisar seus impactos na fiscalização e arrecadação do IPTU no Fisco Municipal de Imperatriz-MA.

Para o efetivo desenvolvimento dos objetivos específicos e a consequente análise e formulação da argumentação, adota-se como processo metodológico uma abordagem quantitativa e qualitativa, com estudo bibliográfico, análise documental e pesquisa de campo através de entrevistas preordenadas. Sem o anseio de estabelecer um discurso definitivo ou juízos de valor sobre as questões pesquisadas, busca-se analisar os conceitos basilares tratados nesta pesquisa, contribuindo com novas reflexões e projeções sobre o objeto de estudo.

\section{CONCEITOS DE BASE: DAS IMUNIDADES TRIBUTÁRIAS E SUA RELAÇÃO COM O IPTU}

Observando-se as relações sociais e institucionais, pode-se notar uma intensa relação entre o Estado e a cobrança de tributos. 0 que no início era uma simples recompensa, paga pelas tribos aos guerreiros mais fortes, em um dado momento passou a ter um caráter impositivo (MONTEIRO, 2018).

Em um Estado Democrático de Direito a soberania ${ }^{3}$ pertence ao povo, como bem denota a Constituição Federal (CRFB), em seu art. $1^{\circ}$, parágrafo único "Todo poder emana do povo" (BRASIL, 2018, p. 22), inclusive o poder tributário. Poder operante do Estado, o qual se manifesta através de uma relação jurídico-tributária que delimita suas competências e, por conseguinte, suas imunidades (MARTINS, 2003)

A competência tributária conceitua-se como uma autorização e limitação constitucional ao exercício do poder tributário do Estado, melhor dizendo, é uma prerrogativa de que são portadores os entes federativos, e que lhes possibilita legislar sobre a produção de leis e normas jurídicas tributárias (CARVALHO, 2012).

Todavia, a imunidade tributária pode ser conceituada como a competência tributária em sentido negativo, sendo assegurada a algumas pessoas, em determinadas situações, afastando o poderio do Estado sobre a imposição de certos tributos, inclusive sua competência (PERES, 2018). Dessa forma, ela veicula-se a um mandamento constitucional ou a lei máxima de uma nação, que afasta não a incidência do tributo, mas a própria competência tributária (RUEDELL, 2013).

A doutrina majoritária conceitua imunidade como limitação ou exclusão da competência de tributar. Entretanto, Paulo Barros de Carvalho (2012) afirma que a imunidade não é uma limitação constitucional à competência tributária, mas ao poder de tributar, pois o que limita a competência vem em sentido contrário a ela, buscando reprimi-la ou amputá-la. Função

3 Nas palavras do constitucionalista Kildare Gonçalves Carvalho: "É a soberania, pois, uma qualidade, a mais elevada, do poder estatal, e não o próprio poder do Estado, significando, no plano interno, supremacia e superioridade do Estado sobre as demais organizações e, no plano externo, independência do Estado em relação aos demais Estados" (CARVALHO, 1999. p. 71). 
que não pertence a norma imunizante, visto que ela colabora com o desenho do campo de competência na esfera constitucional, nos quais as pessoas políticas haverão de operar.

Dessa forma, se incluem nas limitações constitucionais ao poder tributante, além das competências tributárias entre os entes federados, os princípios da legalidade, anterioridade, irretroatividade, capacidade contributiva, isonomia, vedação ao confisco, e a própria imunidade tributária (SCAFF, 2018).

\subsection{PARALELO ENTRE IMUNIDADE, ISENÇÃO E NÃO INCIDÊNCIA}

Precedentemente à continuidade do estudo das imunidades, se faz necessário a sua distinção do instituto da isenção e da não incidência.

A imunidade tributária, conforme o que foi citado, nasce de uma norma constitucional que estabelece a incompetência dos entes tributantes para expedir regras instituidoras de fatos geradores (WIESE, 2012, p. 14). Nela não há a obrigação tributária, pois não ocorre o fato gerador do tributo descrito pela hipótese de incidência.

A isenção ao contrário da imunidade, encontra-se no plano infraconstitucional, no qual o legislador dispensa o contribuinte do pagamento do tributo. Nesse caso, há a ocorrência do fato gerador descrito pela hipótese de incidência surgindo a obrigação, entretanto, não ocorre o lançamento do tributo, e, por conseguinte, não se constitui o crédito tributário.

Já a não incidência está ligada a própria norma de tributação, aquela que descreve a hipótese de incidência do tributo: "Esta norma descreve a situação de fato, que quando realizada, faz nascer o dever jurídico de pagar o tributo. Tudo o que não esteja abrangido por tal descrição constitui hipótese de não incidência tributária." (WIESE, 2012, p. 24).

Em síntese, a isenção é exceção legalmente qualificada por outra Lei, a imunidade é a vedação constitucional à tributação e a não incidência é fato deixado de fora da tributação pelo legislador, seja expressamente ou tacitamente (WIESE, 2012, p. 25).

\subsection{DA IMUNIDADE TRIBUTÁRIA RECÍPROCA}

$\mathrm{O}$ art. 150, VI, da Constituição Federal elenca os diversos tipos de imunidades, como a imunidade tributária recíproca, a imunidade religiosa, a imunidade de partidos políticos, dentre outros.

A imunidade recíproca (art. 150, IV, "a" da CF/88) é a impossibilidade de cobrança de impostos pelos entes federados sobre rendas, patrimônio e serviços uns dos outros.

Ela surge primeiramente com a independência das colônias americanas da corte britânica, no projeto federalista, elaborado por Alexander Hamilton, James Madison e John Jay. Em seu surgimento, tinha como objetivo instigar a capacidade do novo governo de se auto financiar, pois o dinheiro era e ainda é considerado uma ferramenta essencial do organismo político, é aquele que sustenta a vida, movimenta e capacita o Estado na execução de suas funções essenciais. (HAMILTON, 2003). 
Surge então, no contexto americano, um "federalismo de competição", cuja rivalidade entre os Estados (lado forte) e o governo central (lado franco), somado a ausência de uma regra constitucional sobre determinadas competências, propiciaram o julgamento do caso McCulloch v. Maryland, em 1819, considerado como a origem da imunidade tributária, ou em termos próprios o princípio da reciprocal immunity of federal and state instrumentalitie (BALEEIRO, 2015).

Em 1791, é criado o Banco dos Estados Unidos da América a fim de regular o comércio e a moeda por todo território nacional. Alguns anos depois, o banco estabeleceu uma filial na cidade de Baltimore no Estado de Maryland.

Destarte, o Estado começou a exigir dessa sucursal o imposto sobre a selagem das estampilhas, ato que foi rechaçado pelo então caixa do banco o senhor James McCulloch.

O entrave foi levado à Suprema Corte em 1819, então presidida pelo Chief of Justice Jonh Marshall. Tal julgamento buscava responder duas perguntas diversas, a primeira era se o Congresso tinha o poder de criar um banco, bem como estabelecer filiais; a segunda questão era se o Estado de Maryland poderia taxar a filial do banco sem violar a Constituição.

Segundo Marshall, a resposta da primeira pergunta se encontrava na autonomia dada a União para cada Estado federado na promulgação de sua Constituição. Pois, embora os poderes da União fossem limitados, seu governo era supremo dentre os demais e, suas leis, assim que elaboradas em observância a Constituição, tornavam-se supremas no país.

Nesse sentido, a Constituição Americana dava ao Congresso o poder de elaborar quaisquer leis que se fizessem necessárias para o exercício pleno de seus poderes, fato que justificava a possibilidade de criação do Banco dos Estados Unidos bem como de sua filial.

O entendimento da suprema corte relembra a teoria dos poderes implícitos, tese defendida por Alexander Hamilton, segundo o qual, embora a Constituição não explicite em seus dispositivos normativos determinados poderes, estes lhe estariam sujeitos implicitamente no corpo jurídico e em seus demais artigos.

Por sua vez, na busca da resposta a segunda pergunta (a possibilidade de tributação), se estabeleceu a tese da imunidade recíproca, criada sob os seguintes axiomas (LIMA, 2011):

a) 0 poder de criar implica o poder de preservar;

b) O poder de destruir, quando exercido por um estranho, é hostil e incompatível com os poderes de criar e preservar;

c) Sempre que tal incongruência existe, aquela autoridade que é suprema deve prevalecer.

No contexto jurídico brasileiro, a forma federativa de estado adveio com a proclamação da república em 1889. Uma vez que a federação é definida como forma de Estado, tal fato traz como reflexo a incidência do princípio federativo para o ordenamento pátrio (ARENHART, 2013).

Fazendo essa relação entre a tributação e autonomia de cada ente federado, Almicar de Araújo Falcão (1957, p. 3-4) leciona que a previsão da imunidade recíproca no ordenamento jurídico visa "resguardar a incolumidade do regime federativo, evitando que as unidades federadas interfiram, pela via da tributação, na área de competência e autonomia uma das outras". Portanto, a autonomia é o princípio jurídico motriz do dever de reciprocidade. 
O segundo princípio que fundamenta a existência da imunidade recíproca é o princípio da isonomia. Ora, se na relação de tributação, em uma primeira análise, existe uma supremacia de quem tributa sobre quem é tributado, logo não se pode tributar os entes federativos. Pois entre as pessoas políticas reina a mais absoluta igualdade jurídica. "Uma não se sobrepõe às outras. Não, pelo menos, em termos jurídicos. É o quanto basta para afastarmos qualquer ideia de que podem sujeitar-se a impostos." (QUEIROZ, 2017, p. 67).

\subsection{DO IMPOSTO SOBRE A PROPRIEDADE PREDIAL}

\section{E TERRITORIAL URBANA - IPTU}

A regra matriz de incidência tributária é conhecida também como a norma tributária, sendo uma espécie de norma jurídica, possuindo a capacidade de definir a incidência fiscal do tributo. Esta se configura inicialmente como um conjunto de juízos hipotéticos-condicionais (CARVALHO, 2012, p. 171), havendo uma hipótese no antecedente e um mandamento no consequente.

$\mathrm{Na}$ hipótese, encontra-se um critério material (comportamento de uma pessoa), condicionado no tempo (critério temporal) e no espaço (critério espacial). Já na consequência, depara-se com um critério pessoal (sujeito ativo e sujeito passivo) e um critério quantitativo (base de cálculo e alíquota). A junção desses dois dados resulta na possibilidade de exibir, de forma plena, o núcleo lógico-estrutural da norma-padrão de incidência tributária (CARVALHO, 2012).

Conforme dispõe o art. 156, I da CF/88, o IPTU incidirá sobre a propriedade predial e territorial urbana localizados na zona urbana do município. Assim, o aspecto material da regra-matriz de incidência do IPTU, como bem menciona Furlan (2010), é a situação de ser proprietário do bem imóvel.

0 aspecto espacial reputa-se ao conjunto que delimitam o lugar de ocorrência do fato gerador. 0 Código Tributário Nacional (CTN) em seu art. 32, § $1^{\circ}$ traz uma definição geral de delimitação do perímetro urbano dos municípios em todo país.

Para tanto, qualquer área que contenha ao menos dois melhoramentos explicitado pelos incisos do $\S 1^{\circ}$ do art. 32 do CTN poderá, conforme lei municipal tornar-se zona urbana e passível de aplicação do IPTU.

0 aspecto temporal da norma de incidência refere-se ao momento em que nasce a obrigação tributária, tendo como regra e, seguida pela grande maioria dos municípios, o dia $1^{\circ}$ de janeiro de cada exercício como momento de lançamento do IPTU.

O aspecto pessoal, refere-se as pessoas representadas nessa relação jurídico-tributária, que conforme o art. 34 do CTN, tem como contribuinte o proprietário do imóvel, o titular de seu domínio útil e o possuidor a qualquer título.

Compõem o aspecto quantitativo da regra matriz de incidência a base de cálculo, que conforme disposto no art. 33 do CTN, é o valor venal do imóvel, não incluindo o valor dos bens móveis que nele estejam permanentemente ou temporariamente. Ela também é composta pela alíquota, sendo está um percentual acrescido a base, possibilitando um valor exato do 
tributo. As alíquotas precisam ser fixadas em lei municipal, observando o princípio da capacidade econômica e do não confisco (SÁ, 2013).

A CF em seu $\S 4^{\circ}$ do art. 182, acentua ainda que na composição da base de cálculo poderá incidir um caráter progressivo do IPTU, autorizando o Poder Público Municipal mediante lei específica, observada a lei federal, exigir do proprietário do solo urbano não edificado, subutilizado ou não utilizado, que promova sua adequação sob pena de cobrança progressiva do IPTU.

Muitos são os doutrinadores que consideram o caráter progressivo do IPTU como um instrumento regulador da função social da propriedade. Nesse sentido, Carrazza (2019) relaciona a progressividade do IPTU com a capacidade de pagamento dos contribuintes. Argumenta o respectivo autor que a busca de igualdade entre estes deve ser norteada pelo princípio da isonomia, alçando a superação das injustiças e desigualdades sociais (TRINDADE; RIBEIRO, 2018).

\section{DA CONCESSÃO DE USO DE BENS PÚBLICOS POR PARTICULARES}

Não existe uniformidade de pensamento entre os doutrinadores sobre a definição do conceito de concessão. Grande parte dos autores italianos, em especial Cino Vitta (1962), atribui ao vocábulo concessão, à acepção de todo e qualquer ato da Administração Pública que outorgue direitos ou poderes ao particular.

Por outro lado, autores como Santi Romano (2008) tem uma perspectiva restritiva, dividindo-a em duas espécies: translativa e constitutiva, admitindo-se em acréscimo a existência de concessão de serviço público, de obras públicas e de uso de bens públicos, pensamento também compartilhado pela maioria dos autores franceses. E por último, temos os doutrinadores que atribuem ao termo concessão tão somente às espécies de serviços públicos.

O direito brasileiro admite as seguintes modalidades de concessão:

a) Concessão de serviço público, em sua forma tradicional, conforme dispõe a Lei $n^{\circ} 8.987$ de 1995 ;

b) Concessão patrocinada, prevista na Lei nº 11.079 de 2004, é uma espécie de parceria público-privada;

c) Concessão de obra pública, também disciplinada pela Lei n $8.987 / 95$ e pela Lei $n^{\circ} 11.079 / 04$;

d) Concessão administrativa instituída pela Lei $n^{\circ} 11.079$, como uma outra modalidade de parceria público-privada;

e) Concessão de uso de bem público, acrescido ou não de exploração do bem, regularizada por legislação esparsa. Esta é objeto de análise nesta pesquisa.

Portanto, este capítulo se estruturará na conceituação da concessão de uso de bem público bem como suas modalidades e na análise jurisprudencial do tema, frente à possibilidade de cobrança do IPTU sob a ótica do RE 601.720/RJ (STF). 


\subsection{DO CONTRATO DE CONCESSÁO DE USO DE BEM PÚBLICO}

A concessão de uso é um contrato administrativo no qual a Administração Pública transfere ao particular o uso de bem público, cuja natureza "é de contrato de direito público, sinalagmático, oneroso ou gratuito, comutativo e celebrado intuitu personae." (MELO, 2013).

Celso Antonio Bandeira de Melo (2013), compreende que a concessão é o produto de um acordo de vontades entre o concedente e o concessionário, objetivando a formação de um vínculo jurídico que seria regido por normas complementares e unilaterais organizadas pela concedente, sobre os meios, modos e formas que se realizariam o ato jurídico, decorrendo pois de ato convencional e não contratual.

De forma semelhante, pensa também Gaston Jèze (1914), que limita o instituto ao aspecto contratual, isto é, só a concessão de um serviço público, entendendo que não há uma finalidade ou um objeto na ocupação do domínio público, portanto, não haveria um contrato, mas um ato unilateral de gestão do bem público.

O direito brasileiro partilha da tese contratualista, muito bem representada pelo conceito do professor Hely Lopes de Meirelles:

A concessão pode ser remunerada ou gratuita, por tempo certo ou indeterminado, mas deverá ser sempre precedida de autorização legal e, normalmente, de licitação para o contrato. Sua outorga não é nem discricionária nem precária, pois obedece a normas regulamentares e tem a estabilidade relativa dos contratos administrativos, gerando direitos individuais e subjetivos para o concessionário, nos termos do ajuste. Tal contrato confere ao titular da concessão de uso um direito pessoal de uso especial sobre o bem público, privativo e intransferível sem prévio consentimento da Administração, pois é realizado intuito personae, embora admita fins lucrativos. É o que ocorre com a concessão de uso remunerado de um hotel municipal, de áreas em mercado ou de locais para bares e restaurantes em edifícios ou logradouros públicos. (2016, p. 296)

Nesse contexto, a concessão de uso pode ser dividida em duas modalidades, a primeira sendo concessão administrativa de uso, que somente transmite ao concessionário um direito pessoal intransmissível a terceiros. A segunda como a concessão de direito real de uso, que distribui a terceiros por sucessão legítima e testamentária ou por ato inter vivos, o uso de bem como um direito real.

A concessão de direito real, encontra-se regulada no Decreto- Lei ${ }^{\circ}{ }^{\circ} 271$ de 28 de fevereiro de 1967, que no art. $7^{\circ}$ dispõe que a Administração transfere ao particular o uso remunerado ou gratuito de terreno público, como um direito real e resolúvel, respondendo o concessionário por todos os encargos que sobrevenham sobre o imóvel, sejam eles de natureza civil, administrativa ou tributária (SANTOS, 2016).

Entretanto, encontram-se mais algumas diversidades de modalidades de concessão de uso de bens públicos, como a concessão de exploração, onde a administração confere ao concessionário o poder de gestão dominial, podendo este explorar o bem, tendo como exemplo a concessão de exploração de minério, petróleo e extrativismo vegetal. 
Temos também a concessão temporária e de utilidade pública a exemplo a de águas e energia, ou perpétua ou de utilidade privada, como as de sepultura, ou de exploração de campos de algas.

Portanto, é de extrema importância à identificação da natureza jurídica do contrato existente entre a Administração Pública e o terceiro, pois é a partir dele que se verificará a possibilidade de incidência do IPTU sobre o imóvel, sendo este de direito real ou pessoal.

\subsection{UMA ANÁLISE JURISPRUDENCIAL DO RE 601.720/ RJ (STF)}

O plenário do Supremo Tribunal Federal em 19 de abril de 2017 julgou o recurso extraordinário sob o n 601.720/RJ oriundo de uma ação anulatória de débito fiscal, ora promovida pelo Município do Rio de Janeiro para cobrança de IPTU sobre imóvel da União, administrado pela INFRAERO.

O pleito guiou-se na análise da possibilidade de cobrança de IPTU sobre um bem imóvel que embora pertencesse a união, foi concedido a empresa privada exploradora de atividade econômica, Barrafor Veículos Ltda, figurando essa como recorrida no caso em questão.

Em seu voto o Min. Edson Fachin, relator do recurso, relembrou a natureza jurídica da INFRAERO, sendo ela pessoa jurídica de direito privado, constituída na forma de empresa pública sob autorização da Lei $5.862 / 72$, tendo por função a administração, operação e exploração de infraestrutura aeroportuária.

O Código Brasileiro de Aeronáutica (CBA) em seu art. 38 positivou que os aeroportos estão equiparados a bens públicos federais, permitindo que neles existam estabelecimentos empresariais. Anteriormente o STF, em sede de repercussão geral, havia estendido a imunidade tributária à INFRAERO, na qualidade de prestadora de serviço público, nos seguintes termos:

RECURSO. Extraordinário. Imunidade tributária recíproca. Extensão. Empresas públicas prestadoras de serviços públicos. Repercussão geral reconhecida. Precedentes. Reafirmação da jurisprudência. Recurso improvido. É compatível com a Constituição a extensão de imunidade tributária recíproca à Empresa Brasileira de Infraestrututa Aeroportuária - INFRAERO, na qualidade de empresa pública prestadora de serviço público (STF, BRASIL, 2011)4

O relator negou provimento ao recurso declarando que o contrato de concessão estabelecido entre as partes é de natureza obrigacional. Porém, mesmo estando a concessionária com a posse direta do bem, trata-se de relação precária, permanecendo ainda, a propriedade na esfera patrimonial da União Federal. Não podendo a concessionária, por força de lei municipal, figurar como sujeito passivo da obrigação tributária, porquanto o imóvel é qualificado como bem público federal e, ainda que destinado a exploração econômica, é imune a tributos conforme dispõe o art. 150, VI, "a" da CF/88.

Entretanto, o Min. Alexandre de Moraes, ao argumentar a origem das normas de imunidade, relembrou alguns casos julgados pela corte americana, como por exemplo, o de Helvering v. Power e Allen v. Regents of University of Georgia, onde se determinou que "as

4 Trata-se do ARE-RG 638.315, Rel. Min. Cezar Peluso, DJe 31.08.2011. 
imunidades recíprocas deveriam ser aplicadas somente em relação ao exercício das competências governamentais, não tendo incidência nas questões de natureza comercial" (BRASIL, 2017)

O supracitado ministro reafirmou a interpretação dada pela Corte ao significado jurídico da imunidade recíproca, sendo ela uma verdadeira garantia de preservação do sistema federativo, acrescentando ele que a legitimação da imunidade se dá de fato através da vinculação às finalidades públicas do Estado.

Fazendo alusão ao voto do Min. Joaquim Barbosa na relatoria do RE 434.251, e a interpretação dada por ele ao art. 150, VI, a, é possível condicionar a aplicação da imunidade recíproca pela observação de três quesitos:

1) A imunidade deve abranger as propriedades, bens e serviços dos entes federativos que à utilizem na satisfação de seus objetivos institucionais;

2) O bem, explorado economicamente, cuja destinação seja exclusivamente ao aumento do patrimônio do Estado ou de particulares, deve ser tributado;

3) A desoneração do pagamento do tributo não pode favorecer a quebra do princípio da livre-concorrência, ou do exercício de atividade lícita.

Portanto, se o contrato de concessão transfere o uso do imóvel a outrem, e este é usado para alcançar finalidades que não as de interesse público, ocasionará a propriedade a perda de seu atributo social como bem público, ou seja, sua desafetação, satisfazendo os objetivos e finalidades de interesse privado, com consequências extensivas ao segmento competitivo econômico ${ }^{5}$.

É importante ressaltar o pensamento expressado pelo Min. Luís Roberto Barroso a despeito dos contratos de concessão. Segundo ele, esses contratos, em sua maioria, são de longa duração, com prazo inicial de quinze a vinte anos. Dando ao concessionário quase todos os poderes inerentes do proprietário, podendo até modificar o imóvel como assim o queira, configurando essa posse que antes era precária em exclusiva, o que resultaria na possibilidade de incidência do IPTU sobre o imóvel, conforme dispõe o art. 32 do CTN.

[...]Assim entendo, em primeiro lugar, porque a tributação do imóvel pertencente à União mas explorado economicamente por particular não implica risco algum ao equilíbrio entre os entes federados; em segundo, porque a recorrida demonstra capacidade contributiva objetiva, por dedicar-se à atividade de exploração econômica em caráter privado. [...] a imunidade recíproca não beneficia particulares, terceiros que tenham direitos reais em bens das entidades públicas. [...] Reconhecer a aplicabilidade da imunidade recíproca à tributação de imóvel locado a particulares, para exploração de atividade econômica de cunho privado, redundaria, em última análise, em privilegiar a exploração econômica particular, e não o pacto federativo (BRASIL, STF, 2007) .

Por fim, o plenário deu provimento ao recurso, concluindo que o IPTU pode ser lançado sobre imóvel público, quando na posse de empresa privada explorada de atividade econômica com fins lucrativos, afastando a imunidade recíproca à luz do $\S^{\circ}$ do art. 150 da CF/88,

5 Argumento expresso verbalmente pelo Min. Alexandre de Moraes no plenário do julgamento do RE 594.015 e 601.720 em 06/04/17;

6 Trata-se do voto- vista do Min. Joaquim Barbosa no RE. 451.152, Rel. Gilmar Mendes, DJE 27.4.2007, Segunda Turma.p.8-17. 
priorizando o respeito ao pacto federativo através da busca de uma justiça fiscal coerente com a realidade social (PAULSEN; MELO, 2015).

\section{ABORDAGEM EMPÍRICA SOBRE OS REFLEXOS DA JURISPRUDÊNCIA ACERCA DA IMUNIDADE RECIIPROCA NA ESFERA MUNICIPAL: CASO DO MUNICÍPIO IMPERATRIZ-MA}

Esse capítulo tem dois objetivos específicos: 1) apresentar o sistema de arrecadação fiscal no Município de Imperatriz- MA, com intuito de reconhecer os problemas, falhas e dificuldades existentes na estrutura tributária municipal; 2) verificar os possíveis reflexos na arrecadação fiscal frente a mudança jurisprudencial gerada pelo RE 601. 729/RJ (STF).

\subsection{PROCEDIMENTOS METODOLÓGICOS DA PESQUISA}

No tocante à metodologia de coleta e análise dos dados, adotou-se nesse trabalho a pesquisa bibliográfica, documental e empírica, possuindo um recorte qualitativo e quantitativo associado a entrevistas preordenadas de natureza exploratória.

O levantamento bibliográfico e documental foi essencial para a construção teórica dessa pesquisa, provendo meios que ajudaram na compreensão dos institutos basilares formadores da teoria, ora expressa no RE 601/729. Compreendendo como pesquisa bibliográfica:

0 levantamento de toda a bibliografia já publicada em forma de livros, revistas, publicações avulsas e imprensa escrita. Sua finalidade é colocar o pesquisador em contato direto com tudo aquilo que foi escrito sobre determinado assunto [...] (MARCONI; LAKATOS, 2011, p. 43-44).

A pesquisa empírica, isto é, análise de campo, foi realizada junto a Secretaria de Planejamento, Fazenda e Gestão Orçamentária (SEFAZGO) da cidade de Imperatriz-MA, tendo sido entrevistados dois auditores-fiscais e um funcionário do setor administrativo. A entrevista se deu com base e um questionário preordenado cujos levantamentos buscavam associar os conhecimentos cadenciados pelo levantamento bibliográfico e a realidade vivenciada pelo fisco municipal na cobrança do IPTU.

Por fim, as informações foram colhidas seguindo as regras éticas da pesquisa. Os entrevistados tiveram suas identidades preservadas e assinaram o termo de consentimento livre e esclarecido. Destaque-se o caráter inovador da pesquisa empírica realizada pela compreensão estrutural do sistema de arrecadação municipal, bem como pelo confrontamento dos dados colhidos em levantamento teórico diante daqueles coletados no campo. 


\subsection{DO SISTEMA DE ARRECADAÇÃO TRIBUTÁRIA NO MUNICÍPIO DE IMPERATRIZ-MA}

Conforme dispõe a Constituição Federal em seu art. 156, é de competência dos Municípios a instituição dos impostos sobre a propriedade predial e territorial urbana (IPTU), sobre a transmissão "Inter vivos" de bens imóveis e de direitos reais sobre imóveis (ITBI) e sobre os serviços de qualquer natureza (ISS). Compondo a receita tributária municipal, além do impostos já mencionados, têm-se também o imposto de renda retido na fonte (IRRF), as taxas e contribuições de melhoria específicas.

O Fisco Municipal de Imperatriz-MA por meio da Secretaria de Planejamento, Fazenda e Gestão Orçamentária (SEFAZGO) se estrutura em três setores, como bem afirmou o entrevistado A, auditor fiscal do município. O primeiro setor é o de Receita, responsável pela cobrança dos tributos, seguido pelo setor de contabilidade, cuja função principal é a de registrar a arrecadação dos exercícios anteriores e, por fim, o setor oçamentário, incumbido da previsão de arrecadação para os exercícios fiscais futuros.

As legislações tributárias que vigoram no município são o Código Tributário Municipal (CTM) Lei Complementar n 001/03; o Código Tributário Nacional (CTN); o Código de Postura Lei $n^{\circ}$ 850/97; a Constituição Federal (CRFB) e a Lei de Zoneamento ${ }^{7}$. Entretanto, encontra-se ainda legislações na esfera tributária municipal, tais como a LC n 04/2007 que dispõe sobre a concessão de benefícios e isenções fiscais, a Lei n 923/2000 que define a área urbana de Imperatriz e a LC n001/2003 que institui o programa de recuperação fiscal - PROFIS.

O Código Tributário Municipal possui a seguinte redação:

Art. $6^{\circ} \mathrm{O}$ sistema tributário municipal é composto por:

I- Impostos:

[...]II- taxas:

a) em razão do exercício do poder de polícia:

1- de fiscalização de localização, de instalação e de funcionamento;

2- de fiscalização sanitária;

3- de fiscalização de anúncio;

[...] III- contribuições:

a) de melhoria, decorrente de obras públicas;

b) de custeio, do serviço de iluminação pública;

Conforme dispõe o CTM em seu art. 14 o IPTU "será devido anualmente e calculado mediante a aplicação sobre o valor venal dos imóveis respectivos, das alíquotas estabelecidas nesta Lei". Sobre a faticidade normativa, o entrevistado $\mathbf{C}$ afirma que o lançamento do imposto em Imperatriz ocorre de fato no mês de março do exercício financeiro respectivo, através dos sistemas SAT e STAR com a emissão de um carnê físico distribuído aos contribuintes em suas residências, sendo todo o procedimento homologado pelo Prefeito.

7 Informação verbal concedida pelo entrevistado B. 08/11/18. Entrevista realizada pelos autores. Imperatriz: 2018. 
No sistema municipal, segundo última atualização 2019, encontra-se discriminadas como imóveis sujeitos a incidência do tributo: as casas, barracos, apartamentos, sobrados, depósitos, templos, indústrias, terrenos, dentre outros.

De acordo com o entrevistado A, em toda a existência do fisco municipal, a SEFAZGO nunca realizou julgamentos administrativos de recursos ou petições, mesmo que o CTM Ihe houvesse outorgado tal procedimento. Restando, ao contribuinte ou terceiro, tão somente a apelação em via judicial. Todavia, essa situação tem se modificado, a partir da organização e escolha de pessoal, com intuito de possibilitar o julgamento de processos contenciosos fiscais.

Ressalta-se que, embora o CTM tenha determinado em seu art. $600^{\circ}$, que o recurso em primeira instância seria recebido por um Procurador, atualmente ele é analisado pelo Secretário da SEFAZGO. Outro aspecto importante suscitado pelo entrevistado A é a composição do Conselho Municipal em segunda instância, cuja renovação se dá de dois em dois, sendo composto por dois representantes da sociedade civil ou entidades de classes, dois auditores, um representante da procuradoria e o próprio secretário municipal.

Na perspectiva do entrevistado A, a presença do Secretário Municipal de Finanças na composição do Conselho em $2^{\circ}$ instância pode causar controvérsias de interesses, pois é ele quem em $1^{\circ}$ instância admite ou não o recurso interposto pelos contribuintes ou terceiros interessados.

8 Dispõe o respectivo artigo: Elaborada a contestação, o processo será remetido à Procuradoria da Fazenda Municipal para proferir a decisão (IMPERATRIZ, 2003). 
De acordo com as informações colhidas pelos pesquisadores, cruzando os dados colhidos nas entrevistas e os dispositivos do Código Tributário Municipal, pode-se elaborar um fluxograma acerca do processo administrativo fiscal em Imperatriz-MA, estruturado da seguinte forma:

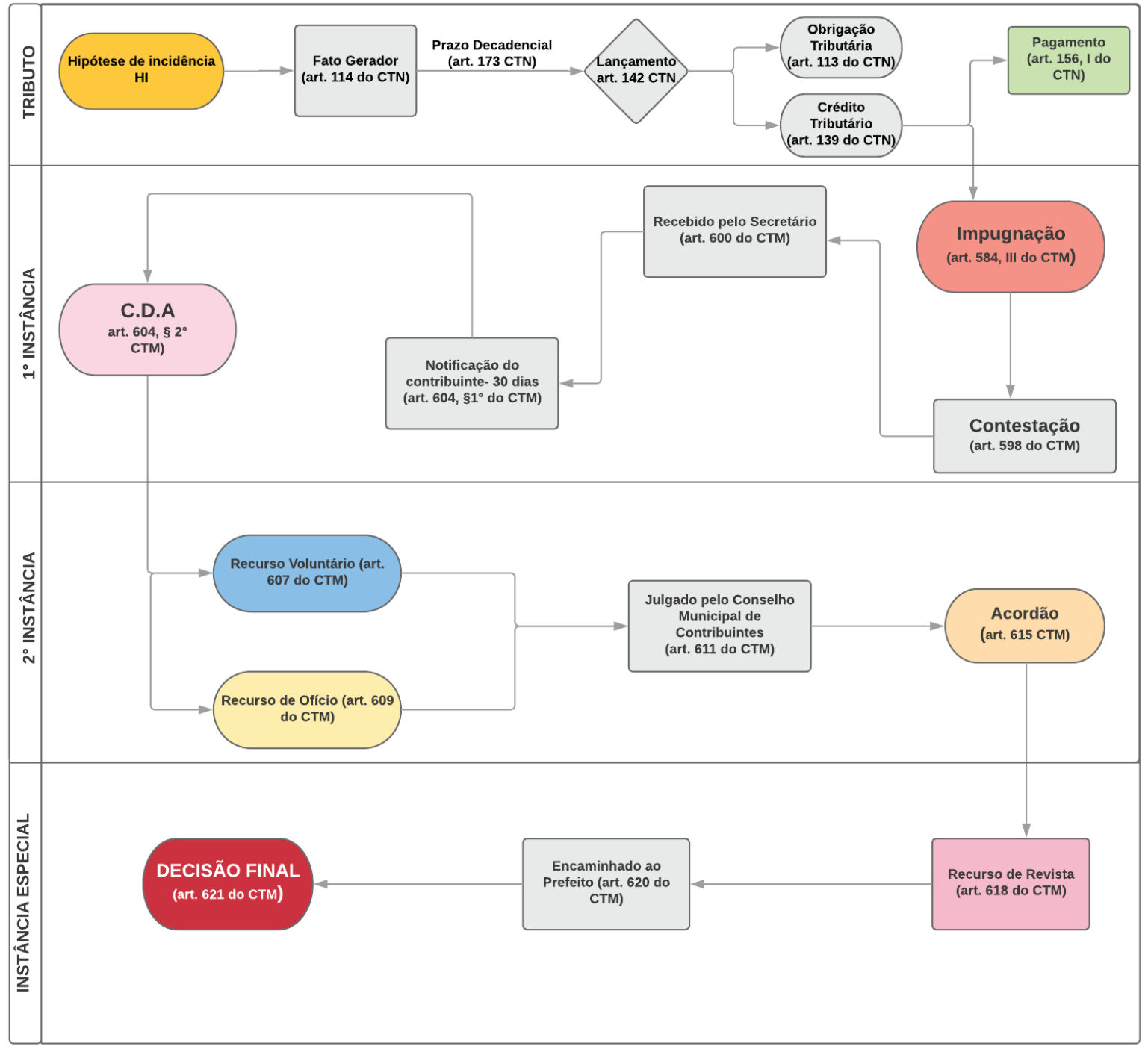

Fonte: Elaboração Própria (2018).

\subsection{DOS IMPACTOS DO RE 601.720/ RJ SOBRE}

\section{A ARRECADAÇÃO MUNICIPAL}

Existem muitos questionamentos jurídicos sobre a aplicação correta do IPTU e a possibilidade de otimização da arrecadação fiscal nos municípios frente aos problemas que se propagam por toda a sua estrutura, tais como problemas de gestão, influências políticas e burocracia injustificada. Essas mazelas estão presentes tanto em âmbito estadual e federal.

Pode-se associar tal fato aos dados trazidos pela autora De Cesare (2005), segundo a qual à arrecadação de IPTU no Brasil é muito mal aproveitada e explorada como fonte de receita pelos municípios. Por sua vez, esse imposto representa 2 a $3 \%$ do PIB dos Esta- 
dos Unidos, Nova Zelândia, Reino Unido e Austrália, enquanto que no Brasil esse percentual chega tão somente a $0,5 \%$ do PIB nacional.

Em análise dos dados recolhidos, pôde-se constatar que o fisco municipal também vivencia tais problemas, uma vez que os entrevistados foram incisivos ao afirmarem que a cobrança de IPTU não alcançava todas as propriedades do município, nem aquelas que estão em seu sistema, estando cadastradas em torno de 125.533 (cento e vinte e cinco mil quinhentos e trinta e três) imóveis.

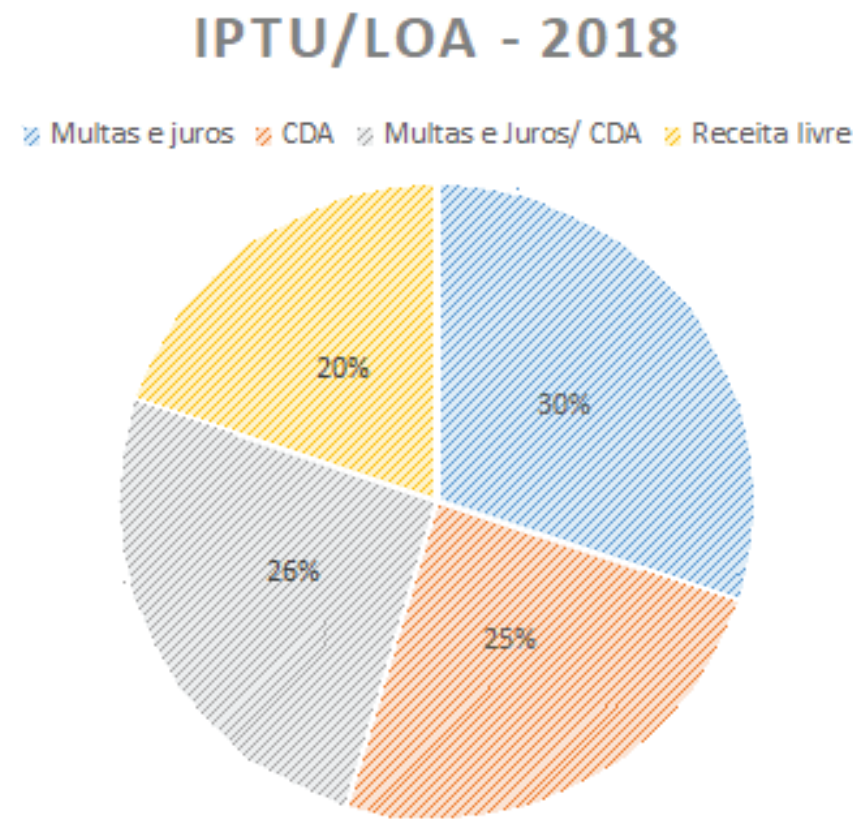

Fonte: Elaboração própria (2018).

Fonte primária: Lei Orçamentária Anual de Imperatriz - MA, 2018.

O gráfico acima demonstra a projeção de arrecadação do IPTU para o exercício financeiro de 2018-2019, deduzidos os fatores de incidência sobre o valor total de arrecadação presentes na LOA, ressaltando-se o fato, segundo o entrevistado $\mathrm{C}$ que o cadastro municipal só alcançar $60 \%$ de tal projeção, situação majorada pela inexistência, no passado, de processos administrativos e a decorrente falha da inscrição dos contribuintes em dívida ativa, estando, por fim, associado a um cadastro obsoleto e insuficiente.

Infelizmente não foi possível auferir dados suficientes para tabelamento do disposição do IPTU nos exercícios de 2019 e 2020.

Dos imóveis públicos abarcados pela regra da imunidade recíproca, só $80 \%$ encontram-se gerenciados pelo fisco municipal. Situação que foi justificada pelo entrevistado $\mathbf{C}$, como produto da ocupação pelo ente federativo de seus próprios bens.

Em relação à existência de imóveis públicos cedidos a particulares na cidade de Imperatriz, o entrevistado $\mathrm{A}$ acredita que não haja nenhum imóvel nesta situação, pois "a grande maioria dos imóveis que o ente municipal ocupa são alugados, sendo de sua propriedade dois imóveis são eles, o prédio onde funciona a Prefeitura e onde se encontra a Secretária de Saúde. Sendo os demais bens públicos do Estado e da União ou a estes equiparados, estão em pleno uso por estes não havendo bens relativamente livres." 
Ambos os entrevistados afirmaram acompanhar as mudanças jurisprudenciais em relação à matéria tributária, entretanto denotaram desconhecer o RE 601.720/ RJ o qual possibilita a cobrança de IPTU sobre imóveis públicos cedidos a particulares quando exploradores de atividade econômica com fins lucrativos.

Conforme verificado na pesquisa de campo, a inexistência de um cadastro com especificação dos imóveis de propriedade da prefeitura, alugados e/ou cedidos impossibilita um real acompanhamento dos impactos da alteração jurisprudencial. As informações apresentadas são baseadas em intuicionismos personalíssimos, não em evidências de transparência administrativa e fiscal.

\section{RESULTADOS E DISCUSSÓES}

O presente capítulo se destina analisar os resultados obtidos pelas entrevistas dos auditores e do funcionário da Secretaria de Planejamento, Fazenda e Gestão Orçamentária (SEFAZGO), associados às hipóteses levantadas no projeto de pesquisa, com a intenção de emitir apontamentos que levem a compreensão fática do objeto deste trabalho.

O que se pôde observar é que o Imposto sobre a propriedade predial e territorial urbana-IPTU é menosprezado pela administração pública, frente aos demais tributos de competência municipal, fato confirmado pelo Entrevistado A. Este atribui ao ISS o posto de tributo com maior relevância atualmente no município, decorrente de terem os auditores adquiridos recentemente um "Certificado Digital" que Ihes dão acesso ao sistema da Receita Federal, facilitando o acompanhamento da arrecadação do ISS pelo Simples Nacional e a posterior inscrição dos contribuintes em dívida ativa.

O pesquisador José Roberto R. Afonso (2014) afirmava que em 2007 a arrecadação nacional do IPTU não chegava a R\$ 50 (cinquenta reais) por habitante, valor que se altera ao longo do território nacional, haja vista, que em alguns municípios o imposto arrecadado não ultrapassava $\mathrm{R} \$ 5$ (cinco reais) por pessoa.

Tal realidade é justificada pela diversidade cultural, econômica e social presente em todo território nacional. Essa heterogeneidade reflete-se no aspecto socioeconômico local, pois não se poderia esperar que um pequeno município tivesse uma grande arrecadação do IPTU, assim como um grande município obtivesse uma arrecadação irrisória frente a sua capacidade tributária.

A primeira hipótese apontada no projeto era que a mudança de entendimento do STF havia valorado o pacto federativo e a ordem econômica consolidando dessa forma a justiça fiscal, bem como possibilitando o aumento da arrecadação fiscal dos municípios.

A suposição acima descrita se confirmou, pois a criação da imunidade recíproca foi concebida com a intenção de proteger o pacto federativo. Vulnerá-lo pela subtração de uma exação do município é violar o princípio da livre concorrência e da ordem econômica ${ }^{9}$. 
Subsequentemente, têm-se a hipótese de o município de Imperatriz-MA não estar preparado para cobrança do IPTU sobre bens públicos que estivessem na posse de empresas privadas perante a precariedade de seu sistema fiscal. Esta proposição também se confirmou, conforme demonstrado nos relatos que foram descritos no capítulo anterior.

Consoante os entrevistados, o último cadastramento que ocorreu em Imperatriz foi no ano de 2004, descrições estas que se encontra em anotações a lapiseira, desatualizadas e inconsistentes. Situação potencializada pela falta de pessoal especializado. Ademais, o município só possui 3 (três) auditores-fiscais, número inadequado a demanda local.

Por última hipótese, afirmou-se que a fiscalização plena do IPTU só seria possível, antes de tudo, se o município realiza-se um estudo pormenorizado de seu sistema, com intuito de identificar suas falhas e dificuldades, desejando otimizá-lo

Essa é a terceira hipótese que se confirmou diante da análise de campo, sendo notório a necessidade que o fisco municipal tem de compreenderem a importância do IPTU e a sua correta cobrança. Na coleta de dados, foi destacado por todos os entrevistados projetos municipais para melhoria do sistema de arrecadação tributária, tais como a renovação da estrutura física local, a formulação de um novo CTM, a compra de um novo sistema que possibilitará a análise conjunta de todos os tributos municipais e o recadastramento do imóveis por meio de um sistema de geoprocessamento. Medidas existentes apenas no plano do devir. Por sua vez, a realidade ainda é um sistema de arrecadação moroso, burocrático e hermético.

\section{CONSIDERAÇÕES FINAIS}

O estudo sobre o RE 601.720/RJ, mostrou a mudança de entendimento do Supremo Tribunal Federal sobre o conceito de imunidade recíproca, objetivando a realização da justiça fiscal e a proteção do pacto federativo, bem como a manutenção da livre concorrência e da ordem econômica. A renovação jurisprudência provocou a necessidade de reestruturação do sistema de arrecadação fiscal dos municípios, que se efetivado, possibilitaria o aumento da arrecadação e a probabilidade de extensão do custeio de suas despesas.

A compreensão do instituto da imunidade recíproca, aplicada ao imposto sobre a propriedade predial e territorial urbana - IPTU, revelou ser de grande importância para a delimitação do campo de incidência do tributo, viabilizando a correta demarcação de seu aspecto material, espacial, temporal e pessoal.

De igual modo, o levantamento dos conceitos e modalidades das formas de cessão dos bens públicos, em especial do contrato de concessão e a análise jurisprudencial do RE 601.720/ RJ, permitiu a percepção dos argumentos levantados pelos ministros no julgamento e a consequente evolução da suprema corte quanto a preservação do sistema federativo.

Destarte, a busca dos impactos na arrecadação fiscal de Imperatriz-MA após o julgamento do RE 601.720/RJ, não ter alcançado os resultados inicialmente almejados, foi possível analisar o sistema de arrecadação do município e, identificar as falhas e problemas em toda sua estrutura, o que possibilitaria sua otimização e possível restruturação. 
Restou demonstrado que a três hipóteses levantadas no projeto de pesquisa, explicadas detalhadamente no capítulo anterior, foram confirmadas. O que leva a refletir acerca dos impactos causadas na Administração Pública municipal em decorrência de um sistema fiscal ineficiente. Ao observar que o Estado não é autossuficiente e adquire renda ao tributar os indivíduos, imagina-se que ele deveria a todo custo valorizar a sua arrecadação monetária, porém não é o que ocorre.

Verifica-se que na cidade de Imperatriz-MA há um sistema fiscal ineficiente, notadamente em sua capacidade de realizar sua função primária que é a arrecadação. No fisco municipal analisado existe grande défice de mão de obra, de investimento em tecnologias, de recursos e principalmente de falta de interesse das autoridades responsáveis pelo planejamento fiscal.

Um sistema arrecadatório eficiente é preciso para um planejamento fiscal que possa garantir e cumprir os objetivos constitucionais (art. 3, CRFB). Os direitos fundamentais, em que pesem não serem vinculados às reservas orçamentárias, necessitam de recursos para sua efetivação. É uma realidade que não se pode fugir. Trata-se da própria ordem material dos direitos. Portanto, a melhora de um sistema de arrecadação, quando acompanhado de transparência fiscal e respeito à Constituição, não serve apenas ao Estado, mas em última instância, aos próprios contribuintes.

Por fim, esse trabalho não esgotou as possibilidades de pesquisas e estudos sobre o tema, pois esse é vasto e ilimitado, fomentado com seus resultados um norte aos futuros pesquisadores desse tema, como a necessidade de análise das decisões do STF em matéria tributária e a repercussão da mesma sobre as esferas executivas, legislativas e judiciárias.

\section{REFERÊNCIAS}

ARENHART, Fernando Santos. Imunidade recíproca e federalismo: da construção norte-americana à atual posição do STF. Revista brasileira de políticas públicas, Brasília, v. 3, n. 2, julho- dez, 2013.

BALEEIRO, Aliomar. Direito Tributário Brasileiro. $11^{\text {a }}$ Ed. Atualizada por Misabel Abreu Machado Derzi. Rio de Janeiro: Editora Forense, 2015.

BRASIL, Superior Tribunal Federal. Acórdão. Recurso Extraordinário n² 253.472/RJ. Plenário. IPTU- BEM PÚBLICOCESSÃO- PESSOA JURÍDICA DE DIREITO PRIVADO. Incide o imposto Predial e Territorial Urbano considerado bem público cedido a pessoas jurídica de direito privado, sendo esta a devedora. Município do Rio de Janeiro x Barrafor Veículos Ltda. Relator Min. Edson Fachin. STF, Brasília, 19 abr. 2017.

BRASIL, Superior Tribunal Federal. Acórdão. Recurso Extraordinário nº 451.152-5/RJ. Segunda Turma. IPTU. Imóvel da União destinado à exploração comercial. Contrato de concessão de uso. Posse precária e desdobrada. Impossibilidade de a recorrida figurar no polo passivo da obrigação tributária. Precedente. Recurso a que se nega provimento. Município do Rio de Janeiro X Rio Sport Center Academia LTDA. Relator Min. Gilmar mendes. STF, Brasília, 22 de Agosto de 2006.

BRASIL. Constituição Federal de 1988. Promulgada em 5 de outubro de 1988. Disponível em: http://www.planalto. gov.br/ccivil_03/Constituicao/Constituicao.html. Acessada em: 20 Out. 2018.

BRASIL. Supremo Tribunal Federal. Imunidade Tributária, № 861- 10 a 21 de abril de 2017. Disponível em: http:// www.stf.jus.br/arquivo/informativo/documento/informativo861.htm. Acessado em: 04 Out. 2018. 
CANTO, Gilberto de Ulhoa. Algumas considerações sobre a imunidade tributária dos entes públicos. Disponível em: http://bibliotecadigital.fgv.br/ojs/index.php/rda/article/viewArticle/18117. Acessado em: 22 set. 2018.

CARRAZZA, Roque Antonio. Curso de Direito Constitucional Tributário. São Paulo: Editora Malheiros, 2019.

CARVALHO, Kildare Gonçalves. Direito Constitucional Didático. 6. Ed. rev. e atual. Belo Horizonte: DelRey, 1999

CARVALHO, Paulo de Barros. Curso de direito tributário. São Paulo: Saraiva, 2012.

CARVALHO. Ivo César Barreto de. Imunidade Tributária na Visão do STF. Disponível em: http://dspace.idp.edu. br:8080/xmlui/bitstream/handle/123456789/699/Direito\%20Publico\%20n332010_Ivo\%20Cesar\%20Barreto\%20 de\%20Carvalho.pdf?sequence=1.Acessado em: 22 set. 2018 .

COSTA, Dilvanir José da. O sistema da posse no direito civil. Revista de informações legislativas, Brasília, a.35, n 139, Jul-Set, 1998.

CURI, Bruno Mauricio Macedo. Limitações constitucionais ao poder de tributar: análise de sua fundamentabilidade ante a razão pública. Dissertação (mestrado). Universidade Federal Fluminense. Niterói-RJ, 2007.

FALCÃO, Amilcar de Araújo. Autonomia dos Governos locais em matéria tributária. Rio de Janeiro, Revista de Direito Administrativo, v. 38, 1954.

FURLAN, Valéria. IPTU. São Paulo: Editora Malheiros, 2010.

GANEM, Bruna Ribeiro. Incidência do IPTU sobre bens imóveis públicos ocupados por empresas privadas: uma análise crítica da materialidade constitucional do imposto e suas relações com a imunidade tributária recíproca (Tema 437 da Repercussão Geral do STF). Dissertação de Mestrado (Direito Tributário). Universidade Católica de Brasília, Brasília- DF, 2015.

HAMILTON, Alexander. O federalista. Belo Horizonte: Ed. Líder, 2003

IMPERATRIZ. Lei complementar $n^{\circ}$ 0001/2004. Institui o programa de recuperação fiscal no município (PROFIS) e dá outras providencias. Imperatriz: Câmara Municipal, 2004.

IMPERATRIZ. Lei complementar $n^{\circ}$ 001/2003. Dispõe sobre o sistema tributário municipal e as normas gerais de direito tributário aplicáveis ao Município. Imperatriz: Câmara Municipal, 2003.

IMPERATRIZ. Lei complementar $n^{\circ}$ 04/2007. Dispõe sobre a concessão de benefícios e isenções fiscais no âmbito do município de Imperatriz e dá outras providencias. Imperatriz: Câmara Municipal, 2007.

IMPERATRIZ. Lei n 859/97. Dá nova redação a Lei Municipal n²21/78, que institui o Código de Postura do Município de Imperatriz. Imperatriz: Câmara Municipal, 1997.

IMPERATRIZ. Lei no 923/2000. Dispõe sobre a definição da área urbana de Imperatriz e dá outras providencias. Imperatriz: Câmara Municipal, 2000.

IMPERATRIZ. Lei ordinária $n^{0}$ 1.708/2017. Dispõe sobre o plano plurianual do Município de Imperatriz-MA para o quadriênio 2018-2021, e dá outras providências. Imperatriz: Câmara Municipal, 2017.

IMPERATRIZ. Lei ordinária n 1.709/2017. Dispõe sobre as diretrizes orçamentarias para o exercício de 2018, e dá outras providencias. Imperatriz: Câmara Municipal, 2017.

IMPERATRIZ. Lei ordinária $n^{\circ}$ 1.710/2017. Estima a receita e fixa a despesa do Município para o exercício financeiro de 2018. Imperatriz: Câmara Municipal, 2017.

JÉZE, Gaston. Les Principes generaux du droit administratif. Paris: Ed. M. Giard e Briere, 1914.

LIMA. Rogério de Araújo. Os artigos federalistas: a contribuição de James Madison, Alexander Hamilton e Jonh Jay para o surgimento do federalismo no Brasil. Revista de informação legislativa. Brasília, v. 48, n. 192, p. 125136, out/dez. 2011.

LUKIC, Melina de Souza Rocha. A tributação no brasil analisada a partir da abordagem cognitiva de políticas públicas. Revista ética e filosofia política. Juiz de Fora, v. 1, n. 15, p. 8-36, Maio. 2012.

MARCONI, Marina de Andrade; LAKATOS, Eva Maria. Metodologia do trabalho científico: procedimentos básicos, pesquisa bibliográfica, projeto e relatório, publicações e trabalhos científicos. 7 ed. São Paulo: Atlas, 2011. 
MARTINS, Marcelo Guerra. Limitações constitucionais ao poder de tributar. Cadernos de Direito. Piracicaba, v. 2, n. 4, p. 249-278, 2003.

MEIRELLES, Hely Lopes. Direito administrativo brasileiro. 39. ed. São Paulo: Malheiros, 2016.

MELO, Celso Antonio Bandeira de. Curso de Direito Administrativo. 30ª ed. São Paulo: Malheiros, 2013,

MONTEIRO, José Carlos Braga. A relação da história da humanidade e os tributos. Disponível em: http://www. portaltributario.com.br/artigos/relacao-da-historia-humanidade-e-tributos.htm. Acessado em: 26 Out. 2018.

PAULSEN. Leandro; MELO, José Eduardo Soares de. Impostos Federais, Estaduais e Municipais. 9. ed. Porto Alegre: Livraria do Advogado, 2015.

PERES, João Bosco. Competência tributária negativa. As imunidades tributarias. Disponível em: http://www.egov. ufsc.br/portal/sites/default/files/anexos/21272-21273-1-PB.pdf. Acessado em: 22 set. 2018.

QUEIRÓS, Etides Yuri Pereira. Imunidade recíproca: analise do alcance e das limitações da norma imunizante. 2017. Dissertação de Mestrado (Direito Público) Universidade Federal da Bahia, Salvador-BA, 2017.

ROMANO, Santi. O ordenamento jurídico. Tradução de Arno Dal Ri Júnior. Florianópolis: Fundação Boiteux, 2008.

RUEDELL, Claudir Luis. A imunidade tributária e as rendas não relacionadas com as finalidades essenciais das entidades exoneradas. 2013. Dissertação (graduação). Universidade Federal de Santa Maria, Santa Maria/RS, 2013.

SÁ, José Delfino. et. al . Um modelo de otimização para alíquotas do IPTU socialmente mais justas. Revista de Administração Pública, Rio de Janeiro, jan/fev, 2013.

SANTOS, Gustavo Magalhães. Da incidência do IPTU sobre imóveis públicos utilizados por particulares mediante contrato de concessão de uso. 2016. Monografia (Especialização)-Instituto Brasiliense de Direito Público, Brasília- DF, 2016.

SCAFF, Fernando Facury. Cidadania e Imunidade Tributária. Disponível em: https://egov.ufsc.br/portal/sites/ default/files/anexos/21047-21048-1-PB.pdf. Acesso em: 10 de Novembro de 2018.

TRINDADE, Larissa; RIBEIRO, Thiago Bão. Igualdade tributária: uma breve concepção filosófica da igualdade e da jurisprudência do STF. Disponível em: http://www.publicadireito.com.br/artigos/?cod=9c502490400407d6. Acessado em: 20 Nov. 2018.

VITTA, Cino. Diritto amministrativo. Torino: Editrice Torinese, 1962.

WIESE, Hernane Elesbão. Limitações ao poder de tributar- as imunidades tributárias do art. 150, inc. VI e alíneas da constituição federal. 2012. Dissertação (graduação). Universidade Federal de Santa Catarina. Florianópolis/ RJ, 2012.

Recebido/Received: 02.04.2019.

Aprovado/Approved: 09.07.2020. 